\title{
Elaboração e avaliação de um programa de jogos recreativos infantis para o ensino de conceitos a crianças pré-escolares*
}

\author{
João Serapião de Aguiar ${ }^{1}$ \\ Pontifícia Universidade Católica de Campinas
}

\begin{abstract}
Os objetivos deste estudo foram os de investigar a influência de um programa de jogos recreativos infantis sobre a aprendizagem de conceitos básicos em pré-escolares e verificar sua generalização para a situação de sala de aula. Foram sujeitos 40 crianças de três a cinco anos de idade. O delineamento utilizado foi de pré-teste, treinanento, pós-teste e teste de generalização. No pré e no pósteste foi utilizado o Teste de Conceitos Básicos de Boehm. No pré-teste, os alunos tinham maior domínio dos conceitos pertencentes à área de espaço, seguida da de tempo, mistura e quantidade. Após o treino, os melhores desempenhos ocorreram nos conceitos pertencentes à área de espaço, seguida da de quantidade, tempo e mistura. A análise estatística apontou a eficiência da aplicação do programa de jogos recreativos infantis para o domínio e a generalização dos conceitos treinados. Os dados foram discutidos com base em um referencial cognitivista de aprendizagem.

Palavras-chave: Formação de Conceitos, Jogos, Pré-Escola, Psicomotor.
\end{abstract}

\begin{abstract}
Elaboration and evaluation of a program of infantile recreational games for the teaching of concepts to preschool-children

The purposes of this study were to investigate the influence of a program of infantile recreational games on the learning of basic concepts by preschool children and to verify its generalization in the classroom. Forty pupils with age varying from three to five years were subject of this study. The delineation used was pre-test, training, post-test and generalization test. In the pre and post-tests, it was used the Test of Basic Concepts of Boehm. In the pre-test the pupils had a greater command of the concepts related to the areas of space, followed by those of time, mixture and quantity. After the training, the best performance occurred with the concepts related to the areas of space, followed by those of quantity, time and mixture. The statistic analysis pointed out to the efficiency of the application of the infantile games program in order to acquire command and generalization of the drilled concepts. The data were examined under a referencial cognitivist learning basis.
\end{abstract}

Key words: Concepts Formation, Games, Preschool, Psychomotor.

\section{Introdução}

A escola tradicionalmente responsabilizase pela organização de situações formais que permitem a aquisição de conceitos julgados relevantes em determinados momentos da escolaridade infantil.

\footnotetext{
"Este artigo constitui uma versão resumida da Tese de Doutorado elaborada pelo autor, defendida na Faculdade de Educação da UNICAMP, em 1996, sob orientação da Prof $^{a} \mathrm{Dr}^{a}$ Anita Liberalesso Neri.

1. Professor no Instituto de Psicologia e na Faculdade de Educação Física da PUC-Campinas. Endereço para correspondência: Rua Marechal Deodoro, 1099, CEP 13020904, Campinas, SP.
}

Durante o $1^{\circ}$ grau a ênfase recai em processos verbais, principalmente palavras, símbolos e códigos. No nível pré-escolar há acordo entre os estudiosos quanto a se ensinar conceitos por intermédio de atividades lúdicas, mediadas pela linguagem oral, gestual (motora), de objetos e figuras. Há também consenso de que a pré-escola e os primeiros anos da escola de $1^{\circ}$ grau constituem a época por excelência para a aquisição de repertórios conceituais considerados básicos ou pré-requisitos para aquisições acadêmicas posteriores. É o caso, por exemplo, 
do domínio de certos conceitos relativos à orientação no tempo, como antes, após e durante, e à duração dos intervalos, como tempo longo $\mathrm{e}$ tempo curto, que irão, certamente, ter seus reflexos em aprendizagens posteriores.

O jogo é reconhecido como meio de fornecer à criança um ambiente agradável, motivador, planejado e enriquecido, que possibilita a aprendizagem de várias habilidades. $\mathrm{Na}$ idade pré-escolar, mediante a brincadeira e a fantasia, a criança adquire a maior parte de seus repertórios cognitivos, emocionais e sociais. Platão ensinava matemática às crianças em forma de jogo e preconizava que os primeiros anos da criança deveriam ser ocupados com jogos educativos, praticados em comum pelos dois sexos, sob a vigilância e em jardins de crianças (Platão 348 a.C., apud Almeida, 1987). Froebel, que foi o primeiro pedagogo a incluir o jogo no sistema educativo, acreditava que a personalidade da criança pode ser aperfeiçoada e enriquecida pelo brinquedo, e que a principal função do professor, neste caso, é a de fornecer situação e materiais para o jogo. Para o autor, as crianças aprendem através do brincar, admirável instrumento para promover a sua educação (Froebel, 1826, apud Bomtempo, 1974). Claparède (1940) afirma que a criança é um ser feito para brincar e que o jogo é um artifício que a natureza encontrou para envolver a criança numa atividade útil ao seu desenvolvimento físico e mental. Sugere aos educadores que usem o jogo no processo educativo para realizar o ensino mais no nível da criança, fazendo, de seus instintos naturais, aliados, e não, inimigos. Jacquin (1963) enfatiza que o jogo tem sobre a criança o poder de um exercitador universal. Diz que o jogo facilita tanto o progresso da personalidade integral da criança como o progresso de cada uma de suas funções psicológicas, intelectuais e morais.
Partindo da consideração de que as atividades lúdicas podem contribuir para o desenvolvimento intelectual da criança, Cratty (1975) sugere a utilização de atividades motoras sob a forma de jogos para o domínio de conceitos (como, por exemplo, de linhas retas, de curvas, de círculo, de triângulo, de letras minúsculas e maiúsculas, de para cima/para baixo e de esquerda/direita) e para o desenvolvimento de algumas capacidades psicológicas, tais como: memória, avaliação e resolução de problemas.

Piaget (1962 e 1976) diz que a atividade lúdica é o berço obrigatório das atividades intelectuais da criança, sendo, por isso, indispensável à prática educativa. É pelo fato de o jogo ser um meio tão poderoso para a aprendizagem das crianças que em todo lugar onde se consegue transformar em jogo a iniciação à leitura, à escrita ou à matemática, observa-se que as crianças apaixonam-se por essas ocupações, geralmente tidas como maçantes. Os jogos não são apenas uma forma de desafogo ou de entretenimento para gastar a energia das crianças, mas meios que contribuem e enriquecem o desenvolvimento intelectual. Piaget (1976) afirma:

"O jogo é, portanto, sob suas duas formas essenciais, de exercício sensório-motor e de simbolismo, uma assimilação do real à atividade própria, fornecendo a esta seu alimento necessário e transformando o real em função das necessidades múltiplas do eu. Por isso, os métodos ativos de educação das crianças exigem todos que se forneça às criançaı um material conveniente, a fim de que, jogando, elas cheguem a assimilar as realidades intelectuais que, sem isso, permanecem exteriores à inteligência infantil". (p.160) 


\section{Objetivos}

O estudo aqui apresentado teve por objetivos:

- Investigar a influência de um programa de jogos recreativos infantis sobre a aprendizagem de conceitos em crianças pré-escolares, conceitos estes considerados por Boehm (1977) como básicos para o rendimento escolar em seus primeiros anos.

- Verificar a influência desse programa de jogos recreativos infantis, quanto à generalização desses conceitos básicos ensinados em situação de jogo recreativo para a situação de sala de aula.

\section{Método}

\section{Sujeitos}

Foram sujeitos 40 pré-escolares que integravam duas classes (A e B) de Infantil I de um estabelecimento privado que acolhe uma clientela de renda alta e média-alta, na cidade de Campinas, estado de São Paulo. Dezenove eram do sexo masculino; 36 tinham quatro anos, três tinham três e um tinha cinco anos de idade.

\section{Instrumento}

O instrumento de avaliação e guia para a estruturação dos procedimentos de treino foi o Teste de Conceitos Básicos de Boehm (BTBC, 1977), que avalia o domínio de conceitos considerados como necessários para as aprendizagens acadêmicas das primeiras séries escolares.

O conteúdo do BTBC foi testado pela primeira vez em 1967, com alunos de pré-escola e da $1^{\mathrm{a}}, 2^{\mathrm{a}}$ e $3^{\mathrm{a}}$ séries primárias nos Estados Unidos. Nos três anos seguintes, o material foi rea- plicado em crianças de outras 21 cidades, com a finalidade de assegurar características psicométricas. O BTBC foi traduzido e adaptado (nãopadronizado) para o português em 1977, por Rainho.

Boehm considera como básicos 50 conceitos, que agrupou em quatro áreas ou categorias de contexto. As categorias são as seguintes: Espaço, Quantidade, Tempo e Mistura. Dificuldades especiais de classificação podem surgir, quando um conceito cabe em mais de uma categoria. É o que acontece, por exemplo, com os conceitos perto e entre, que podem designar tanto uma relação espacial quanto temporal, e segundo e terceiro, que podem designar tanto relações espaciais quanto temporais, bem como quantidades. Assim, a classificação de conceitos nessas quatro categorias de contextos, de certa forma, é arbitrária, podendo ser sugeridas outras classificações de significado.

O Quadro 1 apresenta a classificação dos conceitos básicos para a aprendizagem nos primeiros anos escolares, segundo a concepção de Boehm. Neste quadro as marcas em negrito indicam a categoria do contexto de cada item, de acordo com o significado no BTBC; outras marcas indicam contextos adicionais, em que o conceito pode ser empregado. Por exemplo, o conceito começar (item 29) é usado como conceito de tempo no BTBC, mas também pode ser usado para expressar relações espaciais. Boehm utiliza a categoria mistura para indicar conceitos que pertencem a mais de uma categoria de contexto no BTBC. 
Quadro I. Classificação dos Conceitos do BTBC

\begin{tabular}{|c|c|c|c|c|}
\hline \multirow[t]{2}{*}{ CONCEITO } & \multicolumn{4}{|c|}{ CATEGORIA DO CONCEITO } \\
\hline & Espaço & Quantidade & Tempo & Mistura \\
\hline 1. No alto & $\mathrm{x}$ & & & \\
\hline 2. Atravessar & $\mathrm{x}$ & & & \\
\hline 3. Afastado & $\mathrm{x}$ & & & \\
\hline 4. Perto & $\mathrm{X}$ & & $\mathrm{x}$ & \\
\hline 5. Dentro & $\mathrm{x}$ & & & \\
\hline 6. Alguns, não muitos & & $\mathrm{x}$ & & \\
\hline 7. Meio & $\mathrm{x}$ & & $\mathrm{x}$ & \\
\hline 8. Poucos & & $\mathrm{x}$ & & \\
\hline 9. O mais afastado & $\mathrm{X}$ & & $\mathrm{x}$ & \\
\hline 10. Em volta & $x$ & & & \\
\hline 11. Acima & $\mathrm{X}$ & & & \\
\hline 12. A mais larga & & $\mathrm{x}$ & & \\
\hline 13. Mais & & $\mathrm{x}$ & & \\
\hline 14. Entre & $\mathrm{x}$ & & $\mathrm{x}$ & \\
\hline 15. Inteiro & & $\mathrm{x}$ & & \\
\hline 16. O mais perto & $\mathrm{x}$ & & $\mathrm{x}$ & \\
\hline 17. Segundo & $\mathrm{x}$ & $x$ & $\mathrm{x}$ & \\
\hline 18. Ponta & $\mathrm{X}$ & & & \\
\hline 19. Vários & & $\mathrm{x}$ & & \\
\hline 20. Atrás & $x$ & & & \\
\hline 21. Em fila & $\mathrm{X}$ & & & \\
\hline 22. Diferente & & & & $\mathrm{x}$ \\
\hline 23. Depois & $\mathrm{X}$ & & $\mathrm{X}$ & \\
\hline 24. Quase & & $\mathrm{x}$ & & \\
\hline 25. Metade & & $x$ & & \\
\hline 26. Centro & $\mathrm{X}$ & & & \\
\hline 27. Tanto quanto & & $\mathrm{x}$ & & \\
\hline 28. Lado & $\mathrm{x}$ & & & \\
\hline 29. Começar & $\mathrm{X}$ & & $\mathrm{x}$ & \\
\hline 30. Outro & & & & $\mathrm{x}$ \\
\hline 31. Iguais & & & & $\mathrm{X}$ \\
\hline 32. Nem o $1^{\circ}$ nem o último & $\mathrm{x}$ & $\mathrm{x}$ & $\mathrm{x}$ & \\
\hline 33. Nunca & & & $\mathrm{x}$ & \\
\hline 34. Debaixo (sob) & $\mathrm{x}$ & & & \\
\hline 35. Semelhante & & & & $x$ \\
\hline 36. Sempre & & & $\mathrm{X}$ & \\
\hline 37. Tamanho médio & & $\mathrm{x}$ & & \\
\hline 38. Lado direito & $\mathrm{x}$ & & & \\
\hline 39. Frente & $\mathrm{x}$ & & & \\
\hline 40. Zero & & $x$ & & \\
\hline 41. Sobre & $\mathrm{x}$ & & & \\
\hline 42. Cada & & $\mathrm{x}$ & & \\
\hline 43. Separadas & $\mathrm{X}$ & & $\mathrm{X}$ & \\
\hline 44. À esquerda & $\mathrm{x}$ & & & \\
\hline 45. Um par & & $\mathrm{x}$ & & \\
\hline 46. Pular & & & & $\mathrm{X}$ \\
\hline 47. O mesmo & & $\mathrm{x}$ & & \\
\hline 48. Em ordem & $\mathrm{x}$ & & & \\
\hline 49. Terceiro & $\mathrm{x}$ & $\mathrm{x}$ & $\mathrm{x}$ & \\
\hline 50. Menos & & $\mathrm{x}$ & & \\
\hline
\end{tabular}


O BTBC permite identificar crianças cujo nível total de domínio de conceitos básicos é baixo. Permite também identificar conceitos em particular que crianças, individualmente ou, em grupos, não dominam perfeitamente. Pode funcionar tanto como instrumento de pesquisa diagnóstica, como recurso para orientar o profissional na estruturação de atividades e seqüências de treino. Foram esses os objetivos que nortearam a utilização do teste neste trabalho. Por isso, e porque o teste não está validado para crianças brasileiras, os resultados dos sujeitos não foram comparados com as normas da prova.

\section{Procedimento}

O BTBC foi usado para avaliar o domínio de conceitos básicos antes e após a aplicação de um programa de treino conceitual composto por 40 sessões de jogos recreativos infantis.

No pré e no pós-teste a seqüência de aplicação das provas seguiu as normas e instruções de aplicação do BTBC. Foram aplicadas no pré e no pós-teste, em uma só sessão, as provas Forma A - Cadernos 1 e 2.

Para efeito do treino os conceitos foram arranjados da seguinte forma:

- Dez como pares relacionados por oposição, ordem e grau, obedecendo as indicações de Boehm (1977) e Gagné (1980), segundo os quais esse arranjo facilita à criança estabelecer relações: o mais afastado/o mais perto; mais/menos; inteiro/metade; segundo/terceiro; atrás/na frente; centro/lado; iguais/semelhantes; nunca/sempre; debaixo/sobre e lado direito/esquerdo.

- Trinta em separado ou um a um, na medida em que não eram relacionais: no alto; atravessar; afastado; perto; dentro; alguns, não muitos; meio; poucos; em volta; acima; a mais larga; entre; ponta; vários; em fila; diferente; depois; quase; tanto quanto; começar; outro; nem o primeiro nem o último; tamanho médio; zero; cada; separadas; um par; pular; o mesmo e em ordem.

A seqüência para o treino de conceitos isolados foi baseada na estrutura do BTBC e, portanto, decidida pela própria seqüência de conceitos do teste. Para os conceitos pareados a seqüência também foi a do teste.

Os jogos adotados foram adaptações de atividades recreativas constantes em manuais para professores e envolviam os conceitos-alvo, que seriam objeto de treinamento. No item 3.5 apresentamos, como exemplo, a descrição de um desses jogos.

Todos os procedimentos foram aplicados às crianças agrupadas em duas classes (A e B), respeitando-se a distribuição decidida pela escola. As duas professoras, previamente orientadas, ficavam no ambiente fazendo registros dos acertos e erros das crianças, tanto nas sessões de avaliação pré e pós, como nas de treinamento, conduzidas pelo autor deste trabalho. Os registros de comportamentos individuais das crianças eram feitos na folha de registro de respostas do BTBC.

$\mathrm{O}$ critério adotado para a passagem de um conceito para o outro foi de $100 \%$ de acertos, para a totalidade das crianças.

As sessões desenvolveram-se de maio a dezembro, em dois encontros semanais de 45 minutos para cada classe, todas realizadas no pátio da escola. Tais sessões iniciavam-se com uma atividade livre, após a qual as crianças eram dispostas no espaço de modo a poderem observar as demonstrações feitas pelo professor-pesquisador, bem como as dos colegas que, em seqüência e individualmente, eram convidados a imitar os desempenhos modelados (Bandura, 1977, 1979 e 1986). As crianças eram orientadas e instruídas individualmente, e da mesma maneira recebiam as confirmações 
de seus acertos e as correções de seus erros, sempre no contexto do jogo que focalizava cada um dos conceitos treinados.

No decorrer do treinamento conceitual com os jogos recreativos, as professoras criavam situações, em sala de aula, envolvendo os conceitos já treinados e dominados pelas crianças, com duplo objetivo. O primeiro era o de auxiliar a manutenção dos comportamentos. O segundo era o de promover as oportunidades para a generalização para situações acadêmicas diversas daquelas vigentes nas sessões de jogos promovidas pelo pesquisador. Essas situações envolviam várias atividades das crianças, com uso de materiais distintos, como lápis e papel, e também com respostas a instruções tais como: "Aponte o colega que está sentado à esquerda de você", dentre outras.

Esses comportamentos das crianças em sala de aula eram individualmente registrados pela professora, em folha de registro de respostas do BTBC.

A emissão de comportamentos de domínio e de generalização em relação a um conceito, por no mínimo $75 \%$ das crianças da classe, em situações de sala de aula, era considerada como indicador de sucesso do treino desse conceito, ensinado através do jogo. Quando tal critério não era alcançado, o conceito era novamente ensinado pelo professorpesquisador, através do mesmo jogo, em outra sessão recreativa, realizada na semana imediata. Quando menos de $25 \%$ das crianças não atingia o critério, a própria professora incumbia-se de administrar procedimentos de retreinamento, em situação de sala de aula.

\section{Material}

Nas sessões de avaliação e de treino com os jogos foram utilizados os seguintes materiais:

- Folha de papel de cartolina branca, colorida e de sulfite. Bolas de vários tamanhos, cores e pesos, de borracha, meia, plástico e couro. Caixas de papelão de formas, tamanhos, cores e pesos diversos. Tubos de papelão de diferentes tamanhos. Garrafas e copos de plástico, de vários tamanhos e cores. Tampinhas de garrafas. Latas vazias de refrigerantes. Canudinhos grossos de refrigerante. Fitas de tecidos leves e coloridos, de largura fina. Barbante fino. Palitos de fósforo. Patinhos de madeira. Mesas de sala de aula, do tipo infantil. Giz de cores. Cestos pequenos de lixo, com altura de 30 centímetros e boca de 25 centímetros, em média. Pedrinhas. Maçãs. Argolas leves de madeira de 20 centímetros de diâmetro. Bonequinhos de brinquedo. Pneus de carro e de bicicleta. Corda elástica. Arcos. Flores de plástico.

As professoras utilizaram, para registro, o material já citado em "procedimentos".

\section{Atividades de ensino através de jogos}

Para cada conceito ensinado foi planejado um objetivo instrucional, que estabelecia qual era o comportamento-alvo pretendido com a atividade. Além disso foram previamente detalhadas as condições de ensino, que nas descrições dos jogos foram desdobradas em três partes (condições, formação e procedimento). Foram elaborados 40 jogos, 10 para os conceitos relacionais e 30 para os não-relacionais. Cada jogo foi apresentado num formulário em forma de ficha, como no exemplo a seguir. (Ver Quadro 2 ). 
Quadro II. Modelo de Ficha de Atividade de Ensino

\begin{tabular}{|c|c|c|c|}
\hline $\begin{array}{c}\text { OBJETIVO } \\
\text { INSTRUCIONAL }\end{array}$ & $\begin{array}{l}\text { CONDIÇÕES DE } \\
\text { ENSINO }\end{array}$ & FORMAÇÃO & PROCEDIMENTO \\
\hline $\begin{array}{l}\text { Identificar, dentre três } \\
\text { caixas de papelão, a } \\
\text { mais larga, colocando } \\
\text { em cima da mesma uma } \\
\text { lata de refrigerante e } \\
\text { posteriormente ten- } \\
\text { tando acertá-la(a cai- } \\
\text { xa) com uma bola de } \\
\text { meia, lançada com uma } \\
\text { ou ambas as mãos. }\end{array}$ & $\begin{array}{l}\text { Expor aos alunos três } \\
\text { caixas de papelão, do } \\
\text { tipo de guardar sapatos, } \\
\text { com a mesma altura e } \\
\text { largura diferentes. } \\
\text { Colocá-las em pé no } \\
\text { chão, uma ao lado da } \\
\text { outra, numa distância } \\
\text { aproximada de meio } \\
\text { metro entre uma outra. } \\
\text { Material: Três caixas de } \\
\text { papelão, do tipo de } \\
\text { guardar sapatos, de al- } \\
\text { tura igual e largura } \\
\text { diferentes, uma bola de } \\
\text { meia e uma lata de re- } \\
\text { frigerante }\end{array}$ & $\begin{array}{l}\text { Aluno em pé, com a bola } \\
\text { em uma das mãos e a lata } \\
\text { de refrigerante em outra, } \\
\text { de frente as caixas de pa- } \\
\text { pelão, atrás de uma linha } \\
\text { demarcada no solo, aproxi- } \\
\text { madamente a três metros } \\
\text { das caixas de papelão. }\end{array}$ & $\begin{array}{l}\text { Ao iniciar o jogo os alunos deverão estar todos } \\
\text { sentados atrás da linha demarcada no solo, de } \\
\text { frente as caixas de papelão. Dada a instrução e } \\
\text { as orientações pelo professor, que especifica a } \\
\text { ação a ser realizada, os alunos, um por vez, } \\
\text { atendendo a chamada do professor, se levan- } \\
\text { tarão e se localizarão em pé atrás da linha de- } \\
\text { marcada no solo, de frente as caixas de } \\
\text { papelão. Ao sinal do professor se dirigirão até } \\
\text { as caixas de papelão e colocarão a lata de re-- } \\
\text { frigerante sobre a mais larga. Voltarão atrás } \\
\text { da linha demarcada no solo e lançarão com } \\
\text { uma ou ambas as mãos, a bola de meia na } \\
\text { caixa de papelão mais larga, tentando acertá- } \\
\text { la. Após a jogada de cada aluno o professor } \\
\text { deve mudar a posição das caixas. No decorrer } \\
\text { do jogo, para aquisição e/ou reforçamento do } \\
\text { conceito, o professor sempre deverá frisar: } \\
\text { - Coloque a lata de refrigerante em cima da } \\
\text { caixa mais larga. Tente acertar com a bola a } \\
\text { caixa mais larga }\end{array}$ \\
\hline
\end{tabular}

\section{Resultados e Discussão}

A análise consistiu na interpretação das estatísticas descritivas dos dados observados, no pré-teste, no pós-teste e no teste de generalização, de forma que se pudesse obter uma visão de como estes dados estavam distribuídos e de como se diferenciavam pelas classes (A e B), por Áreas (Espaço, Tempo, Quantidade e

\section{Mistura) e no Geral.}

Com a finalidade de fazer comparações entre as áreas, calculou-se a proporção de acertos em cada área, isto é, os números de acertos individuais dividido pelo número de perguntas (conceitos do Teste de Boehm) e multiplicado por 100, em cada área correspondente. (Ver Tabela 1).

Tabela 1. Porcentagem de Acertos

\begin{tabular}{|c|c|c|c|c|c|}
\hline \multirow[t]{2}{*}{ CLASSE } & \multirow[t]{2}{*}{ ÁREA } & \multicolumn{3}{|c|}{ TESTE } & \multirow[t]{2}{*}{ GERAL } \\
\hline & & Pré-teste & Pós-teste & Generalização & \\
\hline \multirow[t]{5}{*}{ A } & Espaço & 58,04 & 86,30 & 89,13 & 77,83 \\
\hline & Quantidade & 47,22 & 77,50 & 78,33 & 67,69 \\
\hline & Tempo & 43,75 & 90,00 & 93,75 & 75,83 \\
\hline & Mistura & 50,00 & 80,00 & 94,00 & 74,67 \\
\hline & Geral & 52,20 & 82,80 & 86,10 & 73,70 \\
\hline \multirow[t]{5}{*}{$\mathrm{B}$} & Espaço & 74,35 & 93,70 & 92,39 & 86,81 \\
\hline & Quantidade & 62,22 & 84,17 & 79,44 & 75,28 \\
\hline & Tempo & 87,50 & 98,75 & 97,50 & 94,58 \\
\hline & Mistura & 78,00 & 90,00 & 96,00 & 88,00 \\
\hline & Geral & 71,40 & 90,30 & 88,50 & 83,40 \\
\hline \multirow{5}{*}{$\begin{array}{c}\text { Geral } \\
(\mathrm{A} \in \mathrm{B})\end{array}$} & Espaço & 66,20 & 90,00 & 90,76 & 82,32 \\
\hline & Quantidade & 54,72 & 80,83 & 78,89 & 71,48 \\
\hline & Tempo & 65,62 & 94,37 & 95,62 & 85,21 \\
\hline & Mistura & 64,00 & 85,00 & 95,00 & 81,33 \\
\hline & Geral & 61,80 & 86,55 & 87,30 & 78,55 \\
\hline
\end{tabular}


Como se pode verificar na Tabela 1, considerando as classes A e B, no pré-teste os alunos tiveram maior facilidade em responder as questões referentes às áreas de espaço, tempo e mistura, e maior dificuldade com as da área de quantidade. Já no pós-teste as maiores facilidades encontradas foram nas áreas de tempo, espaço e mistura, e a maior dificuldade foi na área de quantidade. Na generalização a maior facilidade encontrada pelos alunos foi na área de tempo, seguida pela de mistura e espaço, e a maior dificuldade deu-se na área de quantidade. Tendo em vista a percentagem geral nos três testes, pode-se concluir que em ordem crescente de dificuldades, as mesmas ocorreram, respectivamente, nas áreas de tempo, espaço, mistura e quantidade.

A Tabela 2 foi construída levando-se em consideração todas as respostas obtidas nos três testes para cada conceito. Nesta tabela os conceitos estão colocados em ordem crescente de acertos, isto é, estão ordenados de maior a menor dificuldade. Observando a tabela, podemos constatar que os conceitos mais difíceis foram: a mais larga, o segundo, par, terceiro, à esquerda, em ordem, e assim sucessivamente, até os conceitos metade e sobre, que tiveram uma percentagem de acertos menor que a média geral de acertos $(78,55 \%)$. Por outro lado, podese observar que os conceitos mais fáceis, com média geral maior que $96 \%$ de acertos, foram: inteiro, acima, poucos, atrás, mais, em volta, debaixo e dentro, até o conceito separadas, que obteve uma percentagem de acertos acima da média geral.

Continuando a observar a Tabela 2 podese constatar os conceitos que foram mais beneficiados em termos de diferenças das percentagens médias de acertos entre o pré-teste e o pósteste, e o pré-teste e o teste de generalização. Assim, o conceito pular teve, entre os demais conceitos, a maior diferença entre o pré-teste e o pós-teste, e entre o pré-teste e o teste de generalização. Em seguida ao conceito pular, percebe-se que a maior diferença foi para os conceitos cada entre. Dessa maneira, pode-se observar que entre os conceitos mais difíceis, os menos beneficiados foram os conceitos quase, tanto quanto, a mais larga e semelhante.

Em relação aos conceitos mais difíceis para os alunos, os resultados da Tabela 2 mostram que, no pré-teste, 25 conceitos tiveram uma percentagem de acertos menor do que a média geral de acertos $(61,8 \%)$. Esses conceitos foram os de a mais larga, o segundo, par, terceiro, à esquerda, em ordem, quase, tanto quanto, pular, atravessar, zero, entre, menos, cada, afastado, lado direito, começar, metade, sobre, separadas, nem o primeiro nem o último, centro, o mesmo, frente e nunca. Os conceitos mais fáceis, que tiveram uma percentagem de acertos maior que a média geral de acertos, foram os de inteiro, acima, poucos, atrás, mais, em volta, dentro, debaixo, perto, alguns, meio, iguais, o mais próximo, vários, depois, diferente, tamanho médio, lado, outra, no alto, sempre, na ponta, o mais afastado, em fila e semelhante.

Dos conceitos mais fáceis 13 pertencem à área de espaço (acima, atrás, em volta, debaixo, dentro, perto, o mais próximo, meio, no alto, lado, na ponta, em fila e o mais afastado), seis a de quantidade (inteiro, poucos, mais, alguns, vários e tamanho médio), quatro a de mistura (iguais, diferente, outra e semelhante) e dois a de tempo (depois e sempre).

Dos conceitos mais difíceis 12 pertencem à categoria de quantidade (a mais larga, o segundo, par, terceiro, quase, tanto quanto, zero, menos, cada, metade, nem o primeiro nem o último e o mesmo), 10 a de espaço (à esquerda, em ordem, atravessar, entre, afastado, lado direito, sobre, separadas, centro e frente), dois a de tempo (começar e nunca) e um a de mistura (pular). 
Tabela 2. Conceitos ordenados pela percentagem média de acertos em geral

\begin{tabular}{|c|c|c|c|c|c|c|c|c|c|}
\hline \multirow[t]{2}{*}{ Perg. } & \multirow[t]{2}{*}{ Área } & \multirow[t]{2}{*}{ Conceito } & \multicolumn{4}{|c|}{ Percentagem Média de Acertos } & \multicolumn{3}{|c|}{ Diferença da \% Média de Acertos } \\
\hline & & & Em geral & Pré-Teste & Pós-Teste & Generaliz & Pós-Pré & Gen-Pré & (Pós+Gen)/2-Pré \\
\hline 12 & $q$ & A mais larga & 26,67 & 12,5 & 27,5 & 40,0 & ** & $* * *$ & $* *$ \\
\hline 17 & $q$ & O segundo & 39,17 & 20,0 & 50,0 & 47,5 & $* * *$ & $* * *$ & $* * *$ \\
\hline 45 & $q$ & Par & 48,33 & 12,5 & 70,0 & 62,5 & $* * * * * *$ & $* * * * *$ & $* * * * *$ \\
\hline 49 & $q$ & Terceiro & 48,33 & 30,0 & 62,5 & 52,5 & $* * *$ & $* *$ & $* * *$ \\
\hline 44 & e & À esqueda & 50,00 & 25,0 & 62,5 & 62,5 & $* * * *$ & $* * * *$ & $* * * *$ \\
\hline 48 & $\mathrm{e}$ & Em ordem & 50,83 & 22,5 & 65,0 & 65,0 & $* * * *$ & $* * * *$ & $* * * *$ \\
\hline 24 & $q$ & Quase & 53,33 & 45,0 & 60,0 & 55,0 & $* *$ & $*$ & $*$ \\
\hline 27 & $\mathrm{q}$ & Tantas quantas & 55,00 & 37,5 & 70,0 & 57,5 & $* * *$ & $* *$ & $* * *$ \\
\hline 46 & $\mathrm{~m}$ & Pular & 56,67 & 12,5 & 62,5 & 95,0 & $* * * * *$ & $* * * * * * * *$ & $* * * * * * *$ \\
\hline 02 & $\mathrm{e}$ & Atravessar & 60,00 & 37,5 & 57,5 & 85,0 & $* *$ & $* * * * *$ & $* * *$ \\
\hline 40 & $q$ & Zero & 63,33 & 42,5 & 67,5 & 80,0 & $* * *$ & $* * * *$ & $* * *$ \\
\hline 14 & e & Entre & 65,83 & 27,5 & 87,5 & 82,5 & $* * * * * *$ & $* * * * * *$ & $* * * * * *$ \\
\hline 50 & $q$ & Menos & 70,00 & 37,5 & 90,0 & 82,5 & $* * * * *$ & $* * * * *$ & $* * * * *$ \\
\hline 42 & $q$ & Cada & 71,67 & 32,5 & 87,5 & 95,0 & $* * * * * *$ & $* * * * * *$ & $* * * * * *$ \\
\hline 03 & e & Afastado & 72,5 & 47,5 & 85,0 & 85,0 & $* * * *$ & $* * * *$ & $* * * *$ \\
\hline 38 & e & Lado direito & 72,5 & 50,0 & 90,0 & 77,5 & $* * * *$ & $* * *$ & $* * *$ \\
\hline 35 & $\mathrm{~m}$ & Semelhante & 73,33 & 62,5 & 72,5 & 85,0 & * & $* *$ & $* *$ \\
\hline 29 & $\mathrm{t}$ & Começar & 75,83 & 50,0 & 87,5 & 90,0 & $* * * *$ & $* * * *$ & $* * * *$ \\
\hline 25 & $\mathrm{q}$ & Metade & 76,67 & 60,0 & 85,0 & 85,0 & $* * *$ & $* * *$ & $* * *$ \\
\hline 41 & e & Sobre & 76,67 & 55,0 & 87,5 & 87,5 & $* * *$ & $* * *$ & $* * *$ \\
\hline 43 & $\mathrm{e}$ & Separadas & 79,17 & 57,5 & 92,5 & 87,5 & $* * * *$ & $* * *$ & $* * *$ \\
\hline 32 & $q$ & Nem $1^{\circ}$ nem último & 80,00 & 50,0 & 100,0 & 90,0 & $* * * * *$ & $* * * *$ & $* * * * *$ \\
\hline 26 & e & Centro & 80,83 & 47,5 & 100,0 & 95,0 & $* * * * *$ & $* * * * *$ & $* * * * *$ \\
\hline 47 & $q$ & O mesmo & 80,83 & 57,5 & 90,0 & 95,0 & $* * *$ & $* * * *$ & $* * * *$ \\
\hline 09 & $\mathrm{e}$ & O mais afastado & 82,5 & 70,0 & 87,5 & 90,0 & ** & $* *$ & ** \\
\hline 39 & e & Frente & 82,50 & 55,0 & 92,5 & 100,0 & $* * * *$ & $* * * * *$ & $* * * *$ \\
\hline 21 & $\mathrm{e}$ & Em fila & 84,17 & 65,0 & 87,5 & 100,0 & $* *$ & $* * * *$ & $* * *$ \\
\hline 18 & e & Na ponta & 85,00 & 70,0 & 92,5 & 92,5 & $* *$ & ** & $* *$ \\
\hline 33 & $\mathrm{t}$ & Nunca & 85,33 & 57,5 & 100,0 & 100,0 & $* * * *$ & $* * * *$ & $* * * *$ \\
\hline 28 & e & Lado & 86,67 & 77,5 & 92,5 & 90,0 & $* *$ & $*$ & $*$ \\
\hline 36 & $\mathrm{t}$ & Sempre & 87,5 & 70,0 & 95,0 & 97,5 & $* * *$ & $* * *$ & $* * *$ \\
\hline 30 & $\mathrm{~m}$ & Outra & 89,17 & 75,0 & 97,5 & 95,0 & $* *$ & $* *$ & $* *$ \\
\hline 37 & $q$ & Tamanho médio & 89,17 & 80,0 & 95,0 & 92,5 & $* *$ & $*$ & * \\
\hline 01 & $\mathrm{e}$ & No alto & 91,67 & 75,0 & 100,0 & 100,0 & $* * *$ & $* * *$ & $* * *$ \\
\hline 22 & $\mathrm{~m}$ & Diferente & 91,67 & 82,5 & 92,5 & 100,0 & * & $* *$ & * \\
\hline
\end{tabular}




\begin{tabular}{|c|c|c|c|c|c|c|c|c|c|}
\hline \multirow[t]{2}{*}{ Perg. } & \multirow[t]{2}{*}{ Área } & \multirow[t]{2}{*}{ Conceito } & \multicolumn{4}{|c|}{ Percentagem Média de Acertos } & \multicolumn{3}{|c|}{ Diferença da \% Média de Acertos } \\
\hline & & & Em geral ${ }^{*}$ & Pré-Teste & Pós-Teste & Generaliz & Pós-Pré & Gen-Pré & (Pós+Gen)/2-Pré \\
\hline 23 & $\mathrm{t}$ & Depois & 91,67 & 85,0 & 95,0 & 95,0 & $*$ & $*$ & * \\
\hline 19 & $q$ & Vários & 92,50 & 85,0 & 100,0 & 92,5 & $* *$ & * & * \\
\hline 07 & e & Meio & 93,33 & 90,0 & 100,0 & 90,0 & * & & * \\
\hline 06 & $q$ & Alguns & 94,17 & 90,0 & 100,0 & 92,5 & $*$ & & $*$ \\
\hline 16 & e & O mais próximo & 94,17 & 87,5 & 95,0 & 100,0 & * & $*$ & $*$ \\
\hline 04 & e & Perto & 95,83 & 90,0 & 97,5 & 100,0 & $*$ & * & $*$ \\
\hline 31 & $\mathrm{~m}$ & Iguais & 95,83 & 87,5 & 100,0 & 100,0 & $*$ & * & $*$ \\
\hline 05 & $\mathrm{e}$ & Dentro & 96,67 & 95,0 & 97,5 & 97,5 & & & \\
\hline 34 & e & Debaixo & 96,67 & 90,0 & 100,0 & 100,0 & $*$ & $*$ & $*$ \\
\hline 10 & e & Em volta & 98,33 & 95,0 & 100,0 & 100,0 & $*$ & $*$ & $*$ \\
\hline 13 & $q$ & Mais & 98,33 & 95,0 & 100,0 & 100,0 & * & * & $*$ \\
\hline 20 & e & Atrás & 98,33 & 95,0 & 100,0 & 100,0 & $*$ & * & * \\
\hline 08 & $q$ & Poucos & 99,17 & 97,5 & 100,0 & 100,0 & & & \\
\hline 11 & e & Acima & 99,17 & 97,5 & 100,0 & 100,0 & & & \\
\hline 15 & $q$ & Inteiro & 100,0 & 100,0 & 100,0 & 100,0 & & & \\
\hline \multicolumn{3}{|c|}{ Total } & 78,55 & 61,8 & 86,6 & 87,3 & *** & $* * *$ & $* * *$ \\
\hline
\end{tabular}

Nota: Cada '*' vale aproximadamente 10,0 das diferenças

No pós-teste 14 conceitos tiveram uma percentagem menor do que a média geral de acertos $(86,6 \%)$. Desses conceitos oito pertencem à área de quantidade (a mais larga, o segundo, par, terceiro, quase, tanto quanto, zero $\mathrm{e}$ metade), quatro a de espaço (à esquerda, em ordem, atravessar e afastado) e dois a de mistura (pular e semelhante). Na generalização 16 conceitos tiveram uma percentagem menor do que a média geral de acertos $(87,3 \%)$. Desses conceitos nove pertencem à categoria de quantidade (a mais larga, o segundo, par, terceiro, quase, tanto quanto, zero, menos e metade), seis a de espaço (à esquerda, em ordem, atravessar, entre, afastado e lado direito) e um a de mistura (semelhante).

Pelas médias pode-se notar que há um crescimento na média geral de acertos, do préteste para o pós-teste e do pré-teste para a gene- ralização: no primeiro, crescimento de $24,8 \%$, e, no segundo, de 25,5\%. Esse crescimento é indicador de efeito positivo do treino realizado através dos jogos.

Um dos aspectos significativos demonstrado pelos dados é o de que certos conceitos de domínio mais difícil para os alunos mativeramse como tal no pré-teste, no pós-teste e na generalização, apesar do crescimento mostrado na Tabela 2. Esses conceitos, distribuídos pelas áreas, são os de: quantidade (a mais larga, o segundo, par, terceiro, quase, tanto quanto, zero, menos e metade) e espaço (à esquerda, em ordem, atravessar e afastado). Constata-se que a maior dificuldade encontrada pelos alunos foi na área de quantidade.

Para Piaget e Inhelder (1975) e Piaget e Szeminska (1975), o conceito de quantidade é construído pela estruturação do conhecimento 
lógico-matemático, através da abstração reflexiva. Essa construção se dá pouco a pouco, ao decorrer dos anos, e envolve a elaboração de um sistema de relações. Desenvolve-se durante um longo e lento processo, através de um mecanismo mental que abrange o ato de relacionar novas idéias e atividades às anteriores. As crianças em estágio pré-operacional têm dificuldade de entender conceitos que envolvam conservação de elementos, uma vez que o princípio de conservação e de operações reversíveis não são característicos dessa fase. Piaget (1975) diz que na fase sensório-motora e pré-operacional formam-se "pré-conceitos". Na etapa préoperacional a criança tem dificuldade em perceber os elementos comuns de uma relação logicamente necessária, porém tem facilidade em unir elementos que não possuam essa ligação. Dessa maneira, poderá estabelecer conexões entre atos e fatos que logicamente não estão conectados, realizando com isso generalizações indevidas. É o que Piaget (1962) denomina de raciocínio sincrético. Na fase pré-operatória a criança está ligada às configurações (ao aspecto figurativo - representação meramente imagística - que recorre à percepção, à imitação e à imagem mental) e não ao sistema de transformações (aspecto operativo, que é a função própria da estrutura mental operatória). Para Piaget (1967), as operações de adição, subtração, multiplicação e divisão são compreensíveis para as crianças, em média, apenas após os sete anos de idade.

Segundo Piaget e Szeminska (1975), a criança pequena pode lidar apenas com números pequenos, que os consegue compreender, intuitivamente, como figuras perceptíveis. A criança de três anos de idade habitualmente reconhece e conta os algarismos até três, a de quatro até quatro, e a de cinco até cinco. Porém, Wynn (1990) constatou que por volta dos três anos e meio de idade a maioria das crianças que participaram de seu trabalho entendia que o último número usado numa contagem (até três ou quatro) representa a numerosidade dos itens contados. Isso significa que não se deve esquecer que o desenvolvimento não pode ser interpretado apenas à luz da maturação orgânica em termos da idade; há a influência das experiências adquiridas e das aprendizagens que elas provocam, as quais desempenham um papel de relevância no desenvolvimento.

Silva (1995), em trabalho sobre a formação dos possíveis, explica o desenvolvimento das estruturas mentais considerando quatro fatores principais: 1) maturação (considerada como uma extensão da embriogênese), 2) experiência física (que se explica pela interação ativa do sujeito com o meio em que vive); 3) transmissão cultural (educação, idioma etc.) e 4) equilibração (com papel da auto-regulação). Em qualquer abordagem psicológica a ordem e a sucessão de fases do desenvolvimento obedecem a uma evolução ascendente, porém, a idade cronológica média que caracteriza cada uma delas pode sofrer variações de um ambiente para outro em função de experiências adquiridas, advindas de influências sociais e culturais. Sendo assim, a faixa etária dos sujeitos deste trabalho é uma forma para se explicar a maior dificuldade encontrada pelos mesmos na área de quantidade, mas não é a única. Nesta pesquisa de 18 conceitos pertencentes à área de quantidade (a mais longe, o segundo, par, terceiro, quase, tanto quanto, zero, menor, cada, metade, nem o primeiro nem o último, o mesmo, tamanho médio, vários, alguns, poucos, mais e inteiro), tomando-se como base a percentagem média de acertos no pré-teste, no pós-teste e na generalização, os alunos mantiveram a dificuldade em nove deles. Como o nível de desenvolvimento operatório dos sujeitos não foi controlado, não temos dados para fazer afirmações categóricas. 
O que podemos afirmar, com certeza, é que a dificuldade dos alunos foi mantida nos conceitos em que as questões do BTBC exigem mais raciocínio de inter-relações entre elementos, e nesse sentido, eram as mais dificeis.

$\mathrm{Na}$ categoria de espaço, dentre os conceitos que mantiveram níveis de dificuldades estão os conceitos em ordem, afastado e atravessar. No BTBC a questão referente ao conceito $\mathrm{em}$ ordem exige, além de raciocínio de interrelação entre elementos, o de ordenação e de seriação de elementos. A questão pede para ordenar quatro círculos de tamanhos diferentes, partindo do maior para o menor. A questão do conceito de afastado também exige raciocínio de inter-relação entre elementos, ao pedir para identificar a distância relacional entre objetos. A dificuldade mostrada no conceito atravessar deve-se ao próprio significado da palavra, passar de um lado para o outro/passar por através (dentro) de. A questão do BTBC relativa a esse conceito pede para identificar, dentre três figuras - cada uma delas composta por uma bolinha e um pedaço de barbante - , a que contém a bolinha atravessada pelo barbante.

Quanto ao conceito à esquerda, que na área de espaço também manteve nível de dificuldades, Coste (1978) diz que o domínio desse conceito ocorre por volta dos seis anos de idade, é contemporâneo da conscientização do eixo corporal, é precedido pela distinção de à frente/atrás e envolve a distinção de à direita/à esquerda. O reconhecimento de à direita/à esquerda diz respeito não só à maneira como a criança identifica essa diferenciação entre a sua direita e a sua esquerda (também relativa à dominância lateral), mas o modo de como ela a projeta no mundo. Segundo Le Boulch (1983), a apreciação de direções envolve relações entre o corpo e os objetos e o corpo e os indivíduos quanto à orientação no espaço. Essas relações, uma vez sedimentadas em relação ao próprio corpo da criança, atingem um grau de desenvolvimento entre 6 a 8 anos, que a habilitam a efetuar transposições para localizar objetos/ indivíduos no espaço em relação ao seu próprio corpo. $\mathrm{O}$ conceito de lado direito, que teve uma percentagem de acertos menor que a média geral de acertos no pré-teste, também manteve essa situação na generalização. Os melhores índices obtidos por esse conceito, em relação ao conceito de à esquerda, no pré-teste, no pós-teste $\mathrm{e}$ na generalização, podem ser explicados pelo fato de a maioria dos alunos serem destros e provavelmente terem sofrido, ao longo do tempo, maiores treinamentos em referência ao lado direito.

Pela Tabela 2 podem-se identificar os conceitos cuja aprendizagem foi mais beneficiada pelo treino. Esses conceitos são os de: $p u$ lar, entre, cada, nem o primeiro nem o último, par, centro, o mesmo, frente, nunca, à esquerda, em ordem, afastado e começar. Desses conceitos seis pertencem à área de espaço (entre, centro, frente, à esquerda, em ordem e afastado), quatro a de quantidade (cada, nem o primeiro nem o último, par e o mesmo), dois a de tempo (nunca e começar) e um a de mistura (pular). Entre todos, o conceito de pular foi o maior beneficiado com o treino. Esses conceitos tiveram no pré-teste uma percentagem de acertos menor do que a média geral de acertos $(61,8 \%)$, e no pós-teste e na generalização, estão acima das diferenças das percentagens médias de acertos.

A Tabela 1 mostra, considerando as classes A e B, que no pré-teste os alunos tiveram maior facilidade em responder as questões referentes à área de espaço seguidas das de tempo. Esse fato pode ser explicado recorrendo-se ao processo evolutivo nos primeiros anos de vida. Após o período dos primeiros reflexos, das primeiras tendências instintivas e dos primeiros hábitos motores, inicia-se o treino relativo à estruturação espaço-temporal, visando dotar a cri- 
ança de noções básicas para o relacionamento com o mundo que a cerca. Esse treino parte, em princípio, de aspectos centrados na própria criança e posteriormente se traduz num esforço de situá-la num meio ordenado em que ela está incluída como elemento.

A Tabela 1 mostra um efeito de classe, indicando que a classe $\mathrm{B}$ teve melhor desempenho que a classe A. Não se tem dados para explicar a razão desse efeito, uma vez que não foram controladas as variáveis evolutivas e do contexto familiar.

Esta pesquisa teve por objetivo investigar a influência de um programa de jogos recreativos infantis sobre a aprendizagem de conceitos básicos de Boehm (1977) em préescolares e verificar sua influência sobre a generalização para a situação de sala de aula.

Para o ensino de conceitos foi utilizada a educação psicomotora numa concepção que tem por base o princípio da interligação entre a atividade motora e o desenvolvimento cognitivo, e o jogo como forma de ensino, mediados pela linguagem oral, motora, por objetos e figuras.

Foram usados tais procedimentos psicopedagógicos porque são significativos na educação do pré-escolar, principalmente pelo fato de a psicomotricidade fundamentar-se numa filosofia de educação que repousa sobre o conceito unitário da pessoa, e pelo jogo atender às características naturais da criança. A análise dos dados apontou a eficiência pedagógica dos procedimentos envolvidos.

Este estudo, realizado em situação natural, não permitiu controle de variáveis relevantes, como as de desenvolvimento e do contexto familiar. Também não houve controle sobre o que as professoras faziam em classe. Sugere-se que em futuras pesquisas que utilizem este tema como base de estudo, os sujeitos sejam amostrados aleatoriamente, para que suas conclusões resultantes possam ser inferidas para as popu- lações em questão. Dentre as variáveis que podem ser selecionadas para a execução e o controle dessas novas pesquisas, estão as de: acompanhamento de professores em salas de aula, fase de desenvolvimento, das crianças nível de inteligência, origem social, renda familiar e experiência pré-escolar e extra-classe. Esses novos estudos devem estabelecer grupo de controle para isolar melhor os efeitos de fatores de influência.

\section{Referências}

Almeida, P.N. (1987). Educação Lúdica. São Paulo: Edições Loyola.

Bandura, A. (1969). Principles of Behavior Modification. New York: Holt, Rinehart and Winston, Inc. Traduzido para o português por Eva Nick, para a Editora Interamericana Ltda., 1979. . (1977). Social Learning Theory. Englewood Cliffs: Prentice-Hall.

(1986). Social Foundations of Thought and Action. A Social Cognitive Theory. Englewood Cliffs: Prentice-Hall.

Boehm, A.E. (1971). Boehm Test of Concepts. New York: Psychological Corporation. Traduzido para o português por Otacílio Rainho, para o CEPA, 1977.

Bomtempo, E. (1974). Papel do Brinquedo no Controle do Comportamento. Boletim de Psicologia, 25(66), 13-16.

Claparède, E. (s/d). L'Education Fonctionnelle. Traduzido para o português por J.B.Damasco Penna, para a Companhia Editora Nacional, 1940.

Coste, J.C. (1977). La Psychomotricité. Paris: Presses Universitaires de France. Traduzido para o português por Álvaro Cabral, para a Zahar Editores, 1978.

Cratty, B.F. (1973). Intelligence in Action. New Jersey: Prentice-Hall, Inc. Traduzido para o português por Roberto Goldkorn, para a Difel, 1975. 
Gagné, R.N. (1975). Essentials of Learning for Instruction. New York: Holt, Rinehart and Winston, Inc. Traduzido para o português por Rute Vivian Angelo, para a Editora Globo, 1980.

Jacquin, G. (s/d). L'Education par le Jeu. Paris: Éditions Fleurus. Traduzido para o português por Teresa de Araújo Penna, para a Livraria Editora Flamboyant, 1963.

Le Boulch, J. (1980). L'Éducation par le Mouvement - La Psychocinétique a L'âge Scolaire. Paris: Les Éditions ESF. Traduzido para o português por Carlos Eduardo Reis e Bernardina Machado Albuquerque, para a Editora Artes Médicas, 1983.

Piaget, J. (1962). Play, Dreams and Imitation in Childhood. New York: W. W. Norton.

. (1964). Six Études De Psychologie. Genève. Éditions Gonthier S.A. Traduzido para o português por Maria Alice Magalhães D'Amorim e Paulo Sérgio Lima e Silva, para a Editora Forense, 1967.

. (1969). Psychologie et Pedagogie.

Paris: Éditions Denoël. Traduzido para o português por Dirceu Accioly Lindoso e Rosa Maria Ribeiro da Silva, para a Editora Forense Universitária Ltda., 1976.

Piaget, J. e Inhelder, B. (1959). La Genèse des Structures Logiques Elementaires. Suíça: Elachaux et Niestlé, Neuchâtel. Traduzido para o português por Álvaro Cabral, para a Zahar Editores, 1975.

(1962). Le Developpement des Quantités Psysiques chez L'Enfant. Suíça: Delachaux et Niestlé, Neuchâtel. Traduzido para o português por Christiano Monteiro Oiticica, para a Zahar Editores, 1975.

Piaget, J. e Szeminska, A. (1964). La Genèse du Nombre chez L'Enfant. Suíça. Éditions Delachaux et Niestlé, Neuchâtel. Traduzido para o português por Christiano Monteiro Oiticica, para a Zahar Editores, 1975.

Silva, F.H.S. Análise da Interferência de Dois Procedimentos na Aprendizagem Operatória. Dissertação de Mestrado. Campinas: UNICAMP, Faculdade de Educação, 1995.
Wynn, K. (1990). Children's Understanding of Counting. Cognition, 36. 155-193. 